\author{
Jennifer Kryworuchko \\ Daren K. Heyland
}

\section{Using family satisfaction data to improve the processes of care in ICU}

Received: 16 July 2009

Accepted: 17 July 2009

Published online: 3 September 2009

(C) Springer-Verlag 2009

This editorial refers to the article available at:

doi:10.1007/s00134-009-1611-4.

J. Kryworuchko (凶)

School of Nursing, University of Ottawa, (1480B), 451 Smyth Rd, Ottawa, ON K1H-8M5, Canada

e-mail: jkryw032@uottawa.ca

Tel.: +1-613-5625800

Fax: +1-613-5625982

\section{K. Heyland}

Clinical Evaluation Research Unit, Kingston General Hospital, Kingston, ON K7L-2V7, Canada

Critically ill patients in the Intensive Care Unit (ICU) are often unable to appreciate the processes of care; however, the healthcare team also cares for family members who are intertwined in the patient's experience. Families have an important role in sharing relevant information, for example: what transpired before the admission; what kind of person the patient is; and, perhaps most importantly, what the patient would want in terms of care, given the current situation. Increasingly, families are engaged by the healthcare team as partners in decision-making [1]. As a result, researchers are interested in that partnering role of family members, particularly in ways to improve the quality of endof-life decision making in the ICU. An important measure of any improvement strategy is evaluating the satisfaction of family members with the processes of care.

The Family Satisfaction with ICU Care (FS-ICU 24) questionnaire was developed and validated to measure family satisfaction in the critical care setting [2]. The questionnaire consists of two sub-scales: Satisfaction with Overall Care and Satisfaction with Decision Making. The initial version of the questionnaire has been shown to be reliable (correlation coefficient $=0.85$ ), to have both content and construct validity, and to be able to discriminate good from poor ratings of quality in ICUs in Canada [3]. The questionnaire is available in English, Canadian French, Spanish, German, Portuguese, Swedish and Chinese (http://www.criticalcareconnections.com).

In this issue of Intensive Care Medicine, Stricker and colleagues used the FS-ICU 24 to further contribute to what is known about family satisfaction in the ICU [4]. In 2007, they distributed 1,321 questionnaires at 23 adult Swiss-German ICUs and provide here an analysis of the 996 completed questionnaires (response rate 75\%). Consistent with what is found in other ICUs, their results demonstrate a high overall level of satisfaction (mean $78 \%$; SD 14). Satisfaction with care (mean 79; SD 14) is rated by their participants slightly higher than satisfaction with information/decision making (mean 77; SD 15), but the researchers agree that there is still room for improvement. Using a performance-importance grid, these investigators showed that the following elements that are highly correlated with overall satisfaction were infrequently rated as "Excellent": emotional support for family members, consistency, completeness and understanding of information given, coordination of care and assessment and treatment of agitation. This form of analysis is useful as it can be used to prioritize the focus of improvement efforts in the ICU. The authors also found that higher satisfaction with care was associated with higher severity of illness, while a higher patient-tonurse ratio and written admission/discharge criteria were associated with lower overall satisfaction. Others have reported a similar message: there is a need for improvement in end-of-life care, especially in communication and decision making [5-8]. Taken together, these results are a 
call to action to improve the experience of family members in the ICU.

However, do we know enough of their current experience to truly intervene to improve care? Quantitative survey approaches, as discussed above, have some disadvantages. Statistical expressions of association cannot do justice to the complexity of negotiating consensus with and amongst families who are engaged in end-of-life decision-making. Certainly Stricker and colleagues were limited by what they could measure in this quantitative study [4]. There are probably many more pertinent issues that were not investigated, some of which are not measurable quantitatively. For example, an alternative design might have provided some explanation of how the variables that the authors felt were not under the direct control of the healthcare providers (nurse patient ratio, admission and discharge policy, and severity of illness) affected family satisfaction. Analysis of factors present in a family member's wider context may be valuable in understanding how the healthcare team providing care and the broader healthcare system can be more responsive to individual respondents.

Indeed, it is likely that elucidation of the key determinants to family satisfaction will be achieved only by using both quantitative and qualitative research designs. A qualitative research design may reveal variables additional to the system level variables described by the authors and provide a fuller picture of how best to support quality end-of-life decision making. Qualitative interviews and audits of our communication with families can help us to better understand the association between survivorship and satisfaction, how expectations mediate satisfaction, and when and how families want to be engaged in decision making. We know that some families are not even aware that decisions are being made at the end of life and therefore are neither engaged nor involved [9-12]. It would be helpful to better understand how families and their healthcare teams deliberate amongst the options in order to reach consensus about decisions, or whether such consensus is necessary or even desirable.

Engaging patients and families earlier in the decisionmaking process may afford patients the opportunity to share their values and preferences for care before they are incapacitated by their illnesses. We know that preferences change as the context of illness changes and treatments are perceived as increasingly burdensome, resulting in a tipping point - the point at which an individual no longer wishes to endure the burden of treatment and instead prefers to focus on palliation of symptoms. However, families and healthcare providers make decisions for many ICU patients who are critically ill and lack the capacity to make their own decisions. The healthcare team needs to provide support to those who will become the surrogate decision-makers in ICU across transitions in care and along the illness trajectory, so that the families involved have a good understanding of the patient's evolving preferences for treatment.

Finally, as we design and trial interventions targeting improvement of the process of supporting families through the difficult decisions they face, we must continue to attend to how interventions are received by families. We need to report on when, for whom, and in what settings the interventions can be expected to contribute to family satisfaction as well as to the health of individual family members and their family system. Only a broad program of research will be able to build the research base needed to provide high quality care for critically ill patients and for the families who share their journeys.

\section{References}

1. Davidson JE, Powers K, Hedayat KMM, Tieszen M, Kon AAM, Shepard E, Spuhler V, Todres ID, Levy MM, Barr J, Ghandi R, Hirsch G, Armstrong D (2007) Clinical practice guidelines for support of the family in the patientcentered intensive care unit: American College of Critical Care Task Force 2004-2005. Crit Care Med 35:1-18

2. Heyland DK, Tranmer LE (2001) Measuring family satisfaction with care in the intensive care unit: the development of a questionnaire and preliminary results. J Crit Care $16: 142-149$
3. Heyland DK, Rocker GM, Dodek PM, Kutsogiannis DJ, Konopad E, Cook DJ, Peters S, Tranmer JE, O'Callaghan CJ (2002) Family satisfaction with care in the intensive care unit: results of a multiple center study. Crit Care Med 30:1413-1418

4. Stricker KHKO, Zwahlen M, Schmidlin K, Mohr U, Rothan HU (2009) Family satisfaction in the intensive care unit: What makes the difference? Intensive Care Med. doi:10.1007/s00134-009-1611-4

5. Baker R, Wu AW, Teno JM, Kreling B, Damiano AM, Rubin HR, Roach MJ, Wenger NS, Phillips RS, Desbiens NA, Connors AF Jr, Knaus W, Lynn J (2000) Family satisfaction with end-oflife care in seriously ill hospitalized adults. J Am Geriatr Soc 48:S61-S69
6. Wall RJ, Curtis JR, Cooke CR, Engelberg RA (2007) Family satisfaction in the ICU: differences between families of survivors and nonsurvivors. Chest 132:1425-1433

7. Heyland DK, Cook DJ, Rocker GM, Dodek PM, Kutsogiannis DJ, Peters S, Tranmer JE, O'Callaghan CJ (2003) Decision-making in the ICU: perspectives of the substitute decisionmaker. Intensive Care Med 29:75-82

8. Heyland DK, Groll D, Rocker G, Dodek $\mathrm{P}$, Gafni A, Tranmer J, Pichora D, Lazar N, Kutsogiannis J, Shortt S, Lam M for the Canadian Researchers at the End of Life Network (CARENET) (2005) Endof-life care in acute care hospitals in Canada: a quality finish? J Palliat Care 21:142-150 
9. White DB, Curtis JR, Wolf LE, Prendergast TJ, Taichman DB, Kuniyoshi G, Acerra F, Lo B, Luce JM (2007) Life support for patients without a surrogate decision maker: who decides? Ann Intern Med 147:34-40

10. Workman S, Mann OE (2007) 'No control whatsoever': end-of-life care on a medical teaching unit from the perspective of family members. QJM 100:433-440
11. Rodriguez RM, Navarrete E, Schwaber J, McKleroy W, Clouse A, Kerrigan SF, Fortman J (2008) A prospective study of primary surrogate decision makers' knowledge of intensive care. Crit Care Med 36:1633-1636
12. Sprung CL, Woodcock T, Sjokvist $P$, Ricou B, Bulow HH, Lippert A, Maia P, Cohen S, Baras M, Hovilehto S, Ledoux D, Phelan D, Wennberg E,

Schobersberger W (2008) Reasons, considerations, difficulties and documentation of end-of-life decisions in European intensive care units: the ETHICUS Study. Intensive Care Med 34:271-277 